\title{
Influence of hydrodynamic cavitation on the rheological properties and microstructure of formulated Greek-style yogurts
}

\author{
G. H. Meletharayil, ${ }^{* 1}$ L. E. Metzger, ${ }^{*}$ and Hasmukh A. Patel ${ }^{*} \dagger^{2}$ \\ *Midwest Dairy Foods Research Center, Department of Dairy Science, South Dakota State University, Brookings 57007 \\ †Dairy Foods Research and Development, Land O'Lakes Inc., Arden Hills, MN 55126
}

\begin{abstract}
With limited applications of acid whey generated during the manufacture of Greek yogurts, an alternate processing technology to sidestep the dewheying process was developed. Milk protein concentrate (MPC) and carbon dioxide-treated milk protein concentrate (TMPC) were used as sources of protein to fortify skim milk to $9 \%$ (wt/wt) protein for the manufacture of Greek-style yogurts (GSY). The GSY bases were inoculated and fermented with frozen direct vat set yogurt culture to a $\mathrm{pH}$ of 4.6 . Owing to the difference in buffering of MPC and TMPC, GSY with TMPC and MPC exhibited different acidification kinetics, with GSY containing TMPC having a lower fermentation time. The GSY with TMPC had a titratable acidity of $1.45 \%$ lactic acid and was comparable to acidity of commercial Greek yogurt (CGY). Hydrodynamic cavitation at 4 different rotor speeds $(0,15,30$, and $60 \mathrm{~Hz})$ as a postfermentation tool reduced the consistency coefficient (K) of GSY containing TMPC from $79.4 \mathrm{~Pa} \cdot \mathrm{s}^{\mathrm{n}}$ at $0 \mathrm{~Hz}$ to $17.59 \mathrm{~Pa} \cdot \mathrm{s}^{\mathrm{n}}$ at $60 \mathrm{~Hz}$. Similarly for GSY containing MPC, K values decreased from $165.74 \mathrm{~Pa} \cdot \mathrm{s}^{\mathrm{n}}$ at $0 \mathrm{~Hz}$ to $53.04 \mathrm{~Pa} \cdot \mathrm{s}^{\mathrm{n}}$ at $60 \mathrm{~Hz}$. The apparent viscosity $\left(\eta_{100}\right)$ was $0.25 \mathrm{~Pa} \cdot \mathrm{s}$ for GSY containing TMPC and $0.66 \mathrm{~Pa} \cdot \mathrm{s}$ for GSY containing MPC at $60 \mathrm{~Hz}$. The CGY had a $\eta_{100}$ value of $0.74 \mathrm{~Pa}$.s. Small amplitude rheological analysis performed on GSY indicated a loss of elastic modulus dependency on frequency caused by the breakdown of protein interactions with increasing cavitator rotor speeds. A steady decrease in hardness and adhesiveness values of GSY was observed with increasing cavitational intensities. Numbers of grains with a perimeter of $>1 \mathrm{~mm}$ of cavitated GSY with TMPC and MPC were 35 and 13 grains/g of yogurt, respectively, and were lower than 293 grains/g observed in CGY.
\end{abstract}

Received December 16, 2015.

Accepted May 23, 2016.

${ }^{1}$ Current address: PepsiCo Global R\&D, 100 Stevens Avenue, Valhalla, NY 10595.

${ }^{2}$ Corresponding author: HPatel@Landolakes.com
The water-holding capacity of GSY was higher than that observed for a commercial strained Greek yogurt. The ability to scale up the process of hydrodynamic cavitation industrially, and the ease of controlling events of cavitation that can influence final textural properties of the product, make this technology promising for large-scale industrial application. Overall, the current set of experiments employed in the manufacture of GSY, which included the use of TMPC as a protein source in conjunction with hydrodynamic cavitation, could help achieve comparable titratable acidity values, rheological properties, and microstructure to that of a commercial strained Greek yogurt.

Key words: hydrodynamic cavitation, carbon dioxide, Greek yogurt, milk protein concentrate

\section{INTRODUCTION}

The per capita consumption of yogurt in the United States increased from $1.13 \mathrm{~kg}$ in 1980 to $6.76 \mathrm{~kg}$ in 2013 (USDA, 2014). The increased per capita consumption since 2010 is partly believed to be from the increasing popularity of Greek yogurt (GY). A widely used process for the manufacture of GY involves the concentrating of fermented milk solids by dewheying. The process of dewheying in a modern industrial setup employs centrifugal separators like the Quark centrifuge. The acid whey generated from the dewheying process has limited applications owing to its high mineral and lactic acid load. To sidestep the dewheying process, fortifying milk base with high protein milk ingredients is a choice available to GY manufacturers. The GY manufactured by the fortification route is known as Greek-style yogurt (GSY) in the industry. The alternative make process does offer technological challenges in terms of increased fermentation time and altered rheological and microstructural properties. In a study by Desai et al. (2013), sour taste was found to be the dominant sensory defect, whereas increased graininess, higher viscosity, and cohesiveness and decreased melt-away dominated the microstructural and rheological defects in GSY.

In the present study, a 2-pronged strategy was applied to address acidity, rheological, and microstructural de- 
Table 1. Composition of $\mathrm{CO}_{2}$-treated milk protein concentrate (TMPC) powder and milk protein concentrate powder $(\mathrm{MPC})^{1}$

\begin{tabular}{lcccc}
\hline Powder & $\begin{array}{c}\text { TS } \\
(\%, w t / w t)\end{array}$ & $\begin{array}{c}\text { Protein } \\
(\%, w t / w t)\end{array}$ & $\begin{array}{c}\text { Ash } \\
(\%, w t / w t)\end{array}$ & $\begin{array}{c}\text { Calcium } \\
\left(\mathrm{mg}^{-1} \mathrm{~g}^{-1}\right)\end{array}$ \\
\hline TMPC & 96.59 & 71.92 & 4.84 & 12.8 \\
MPC & 95.37 & 67.88 & 6.73 & 19.2 \\
\hline
\end{tabular}

${ }^{1}$ Values are the means of data from triplicate analysis.

fects associated with the manufacture of GSY. Protein fortification by carbon dioxide $\left(\mathrm{CO}_{2}\right)$-treated milk protein concentrate (TMPC) in GSY manufacture could potentially address higher acidity levels on account of its lower buffering when compared with control milk protein concentrate (MPC). The $\mathrm{CO}_{2}$ treatment of milk before and during the process of UF and diafiltration employed in the manufacture of TMPC would partially demineralize milk, leading to the removal of micellar calcium phosphate (MCP) along with serum minerals. The use of hydrodynamic cavitation (HC) as a postfermentation tool was hypothesized to improve the rheological and microstructural properties of GSY. Hydrodynamic cavitation is a process having parallels to acoustic cavitation, with differences arising in the principle of cavity formation. Hydrodynamic cavitation uses velocity and pressure differentials generated by the flow of yogurt inside the cavitator toward the formation of cavities (Gogate and Bhosale, 2013). Pressure differential generates bubbles in low-pressure zones that collapse as they enter a high-pressure zone inside the cavitator. This collapse leads to the release of vast amounts of energy that could potentially influence protein interactions altering rheology and microstructure of GSY. Moreover, grains (that could potentially be a source of graininess) that are formed in GSY could serve as seed nuclei for the bubble to form, expand, and collapse, leading to a product with reduced grains that could lead to a product with superior mouthfeel (Earnshaw, 1998). To prove this hypothesis, the objective of this study was to determine the influence of TMPC as a protein source and hydrodynamic cavitation as a processing step on the chemical, rheological, and microstructural properties of GSY.

\section{MATERIALS AND METHODS}

\section{MPC/TMPC Manufacture and Composition}

The manufacturing procedure and composition (Table 1) of MPC and TMPC powders from pasteurized skim milk $\left(72^{\circ} \mathrm{C}\right.$ for $\left.15 \mathrm{~s}\right)$ are described by Marella et al. (2015). Low heat nonfat dry milk was obtained from Associated Milk Producers (AMPI Inc., New Ulm, $\mathrm{MN})$.

\section{Preparation of Formulated Greek-Style Yogurts}

Pasteurized skim milk was obtained from the Davis dairy plant of South Dakota State University. Nonfat dry milk and MPC or TMPC was added to skim milk at $50^{\circ} \mathrm{C}$. The MPC or TMPC was added to contribute $6 \%$ (wt/wt) protein of the total $9 \%$ (wt/wt) protein in the GSY base formulation. The TS, protein, fat, lactose, and ash content of the GSY base along with the composition of a strained commercial GY purchased from a local grocery store is given in Table 2. The GSY base formulations mixed in a high-speed mixer were heated to $90^{\circ} \mathrm{C}$ for $10 \mathrm{~min}$ in a steam chest followed by cooling to $42^{\circ} \mathrm{C}$. Frozen direct vat set yogurt culture (YC-X11) obtained from Chr. Hansen Inc. (Milwaukee, WI) was added at the rate of $0.02 \%$ ( vol $/ \mathrm{vol})$. The $\mathrm{pH}$ of yogurt bases was measured every hour using a $\mathrm{pH}$ meter (CyberScan pH 110, Eutech Instruments, Singapore) to generate acidification profiles. Fermentation was arrested on reaching a $\mathrm{pH}$ of 4.6 by placing GSY in an ice bath followed by overnight storage in a cold room maintained at $<5^{\circ} \mathrm{C}$. All chemicals and reagents were purchased from Fisher Scientific (Pittsburgh, PA) unless otherwise indicated.

\section{Hydrodynamic Cavitation}

An 8-inch APV hydrodynamic cavitator (SPX Flow Technology, Pasteursvej, Silkeborg, Denmark) was used for the HC of yogurts. The cavitator had specially designed rotors with indentations that influenced the flow trajectory of yogurts inside the cavitator. A total of 66 indentations were placed equidistant from each other on the 200-mm (8-inch) rotor. The speed of rotor that determines the extent of cavitation was controlled with a variable frequency drive attached to a $10-\mathrm{HP}$ motor. The gap between the rotor and stator was $3 \mathrm{~mm}$. The GSY was fed into the cavitator through a positive displacement pump. Four different rotor speeds of 0 , $872,1,745$, and $3,490 \mathrm{rpm}$ corresponding to frequencies of $0,15,30$, and $60 \mathrm{~Hz}$ were used to generate cavitation during yogurt flow through the device. For cavitation at $0 \mathrm{~Hz}$, yogurt was passed through the cavitator with an inactivated rotor. Cavitation was carried out at 8 
Table 2. Compositional analysis (\%, wt/wt; means $\pm \mathrm{SE}$ ) of Greek yogurt base containing $\mathrm{CO}_{2}$-treated milk protein concentrate (TMPC) and milk protein concentrate (MPC), in addition to the compositional analysis (means \pm SE) of a commercial strained Greek yogurt

\begin{tabular}{lccrrr}
\hline Item & TS & Protein & Fat & Lactose \\
\hline Greek-style yogurt base with TMPC & $16.72 \pm 0.03$ & $8.94 \pm 0.05$ & $0.54 \pm 0.01$ & $5.06 \pm 0.03$ & $1.11 \pm 0.05$ \\
Greek-style yogurt base with MPC & $17.37 \pm 0.11$ & $8.97 \pm 0.03$ & $0.37 \pm 0.02$ & $5.3 \pm 0.03$ & $1.27 \pm 0.00$ \\
Commercial strained yogurt & $14.96 \pm 0.06$ & $8.93 \pm 0.08$ & $0.25 \pm 0.05$ & - & $0.73 \pm 0.00$ \\
\hline
\end{tabular}

to $10^{\circ} \mathrm{C}$. Samples cavitated at each frequency were collected and stored below $5^{\circ} \mathrm{C}$ before analysis.

\section{Titratable Acidity}

Titratable acidity (TA) expressed as percentage lactic acid (LAC) per $100 \mathrm{~g}$ of GSY and GY was performed as per the procedure outlined by Bong and Moraru (2014). Approximately $10 \mathrm{~g}$ of yogurt was added to 10 $\mathrm{mL}$ of deionized water followed by the addition of $1 \mathrm{~mL}$ of phenolphthalein $(0.5 \%, \mathrm{wt} / \mathrm{vol})$, followed by titration with $0.1 \mathrm{~N} \mathrm{NaOH}$ to the phenolphthalein end point:

$$
\mathrm{LAC} \%=(9 \times \mathrm{A} \times N) / \mathrm{W},
$$

where $\mathrm{A}$ is the volume in milliliters of the standard 0.1 $N \mathrm{NaOH}$ required for titration, $N$ is the normality of the standard $0.1 \mathrm{~N} \mathrm{NaOH}$ solution, and $\mathrm{W}$ is the weight of the sample expressed in grams.

\section{Rheological Characterization}

Steady rate sweeps and small oscillatory rheological measurements were performed on a stress-controlled rheometer (ATS Rheosystems, Bordentown, NJ). A plate and plate geometry (diameter $30 \mathrm{~mm}$ ) with a gap setting of $2 \mathrm{~mm}$ were used for rheological testing. All rheological testing was carried out at $10^{\circ} \mathrm{C}$.

Flow curves were generated by subjecting the GSY and commercial GY to shear rates between 1 and 100 $\mathrm{s}^{-1}$. Delay and integration times were set to $10 \mathrm{~s}$ and the data obtained were fitted to the power law model.

$$
\eta=\kappa \times \gamma^{(n-1)},
$$

where $\eta$ is the viscosity $(\mathrm{Pa} \cdot \mathrm{s}), n$ is the flow behavior index, and $\kappa$ is the consistency coefficient $\left(\mathrm{Pa} \cdot \mathrm{s}^{\mathrm{n}}\right)$.

The frequency dependency on storage and loss modulus of yogurts was determined by first conducting an oscillatory stress sweep at a constant frequency of 0.15 $\mathrm{Hz}$. The stress values at upper limits of the linear viscoelastic region were used to conduct frequency sweeps from 1 to $10 \mathrm{~Hz}$.

\section{Large Deformation Penetration Tests}

Hardness, firmness, and adhesiveness of GSY and GY were measured using a TA-XT ${ }^{\text {plus }}$ Texture Analyzer (Texture Technologies Corp., South Hamilton, MA) equipped with a $5-\mathrm{kg}$ load cell. Yogurts were transferred into cups (i.d. $54 \mathrm{~mm}$ and height $30 \mathrm{~mm}$ ) and penetration tests were conducted using a 0.5 -inch $(1.27 \mathrm{~cm})$ diameter cylindrical probe. A test speed of $0.5 \mathrm{~mm} \cdot \mathrm{s}^{-1}$ and a posttest speed of $0.5 \mathrm{~mm} \cdot \mathrm{s}^{-1}$ to a distance of 15 $\mathrm{mm}$ were applied. The maximum positive force attained during the penetration test was expressed as hardness, and the total positive area was expressed as firmness. Adhesiveness was expressed as the total negative area that was determined during the test.

\section{Grains in Greek-Style Yogurts and Commercial Greek Yogurt}

Grains in GSY and commercial GY was measured as per the method outlined by Remeuf et al. (2003) with modifications. A sample of approximately $0.1 \mathrm{~g}$ of yogurt was dispersed in $10 \mathrm{~mL}$ of water. Following gentle mixing, $500 \mu \mathrm{L}$ of this dispersion was poured into 10 wells of a 12-well cell culture cluster (Fisher Scientific, Pittsburgh, PA). The dispersions in all 10 wells were visualized under a stereomicroscope (SZX16, Olympus, Tokyo, Japan) with light projected from the bottom of the cell culture cluster. Grains appeared as dark objects on a white background, and representative images were captured. Images were analyzed as 8-bit images with ImageJ software (US National Institutes of Health, Bethesda, MD). Grains with perimeter $>1 \mathrm{~mm}$ were enumerated and expressed as the number of grains in $1 \mathrm{~g}$ of yogurt.

\section{Water-Holding Capacity}

Water-holding capacity (WHC) of GSY and GY was performed according to the procedure of Meletharayil et al. (2015). The WHC of the yogurts was expressed as the ratio of the weight of pellet obtained after centrifugation to the weight of the yogurt and expressed in percentage. 


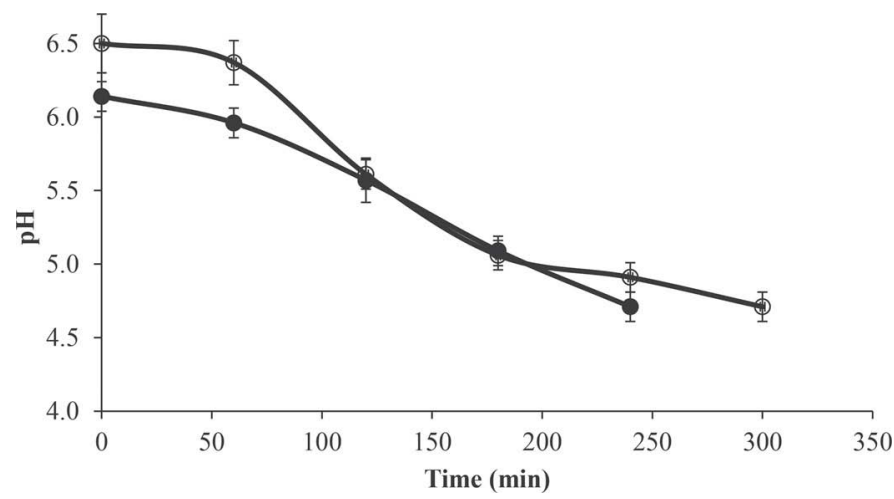

Figure 1. Acidification profiles of Greek-style yogurt (9\% wt/wt, protein) fermented with yogurt culture at $42^{\circ} \mathrm{C}$ containing either milk protein concentrate $(\mathrm{O})$ or $\mathrm{CO}_{2}$-treated milk protein concentrate $(\bullet)$. Error bars indicate SE.

\section{Statistical Analysis}

The ANOVA and significance were indicated by $P$ $<0.05$, using the statistical software SAS (version 9.3, SAS Institute Inc., Cary, NC). Three replicates of GSY were manufactured and each experiment was repeated at least 3 times.

\section{RESULTS}

\section{Mineral and Acidification Profiles of Greek-Style Yogurts}

The protein content of GSY bases was standardized to contain 9\% (wt/wt) protein. Among GSY, yogurts containing MPC had the highest mineral content (Table 2) followed by yogurts containing TMPC. Strained commercial GY had the lowest mineral content among the 3. Compared with GSY with MPC as the protein source, a lower mineral content in GSY containing
TMPC can be attributed to a greater removal of colloidal and serum phase minerals during the process employed in the manufacture of TMPC (Marella et al., 2015). The GSY containing TMPC had significantly lower $(P<0.05)$ fermentation time to reach $\mathrm{pH} 4.6$ as compared with GSY containing MPC (Figure 1). Lower acidification times to achieve $\mathrm{pH}$ of 4.6 in GSY containing TMPC can be correlated with a reduced mineral load leading to a reduction in buffering of the GSY base.

\section{Titratable Acidity}

Titratable acidity (TA) expressed as percentage lactic acid of GSY and GY are shown in Figure 2. The GSY containing TMPC had a TA of $1.45 \%$ (wt/wt) lactic acid compared with $1.95 \%$ (wt/wt) in GSY containing MPC. The TA values of GSY containing TMPC and that of the commercial GY were comparable. The reduced acidity in commercial GY and GSY containing TMPC can be attributed to a reduced buffering due to demineralization during dewheying and $\mathrm{CO}_{2}$ application, respectively.

\section{Rheological Characterization}

The flow characterization properties of the GSY and commercial GY are given in Table 3. All yogurts exhibited a shear thinning behavior, a characteristic behavior of yogurts. The consistency coefficient values $(\kappa)$ and flow behavior index value $(n)$ of GSY was determined by fitting the flow data into a power law equation $\left(\mathrm{R}^{2}\right.$ $>99 \%$ ). The $\kappa$ values of noncavitated GSY were higher than that of the commercial GY, which decreased as GSY were subjected to cavitation. The HC had a greater effect on the flow behavior of GSY containing TMPC with a larger decrease in $\kappa$ and $n$ values as com-

Table 3. Flow characterization (means $\pm \mathrm{SE}$ ) and grains of Greek-style yogurts (GSY) containing $\mathrm{CO}_{2}$-treated milk protein concentrate (TMPC) and GSY with milk protein concentrate $(\mathrm{MPC})^{1}$

\begin{tabular}{|c|c|c|c|c|}
\hline Sample & Flow index $(n)$ & $\begin{array}{c}\text { Consistency } \\
\text { coefficient } \kappa\left(\mathrm{Pa} \cdot \mathrm{S}^{\mathrm{n}}\right)\end{array}$ & $\begin{array}{c}\text { Apparent viscosity } \\
(\mathrm{Pa} \cdot \mathrm{s}, \text { at } 100 \text { shear rate) }\end{array}$ & Grains/g of yogurt \\
\hline \multicolumn{5}{|c|}{ GSY with TMPC } \\
\hline $0 \mathrm{~Hz}$ & $0.07 \pm 0^{\mathrm{ab}}$ & $79.4 \pm 14.4^{\mathrm{bc}}$ & $0.49 \pm 0.01^{\mathrm{de}}$ & $2,389^{\mathrm{a}}$ \\
\hline $15 \mathrm{~Hz}$ & $0.07 \pm 0.04^{\mathrm{ab}}$ & $39.44 \pm 3.85^{\text {cde }}$ & $0.48 \pm 0.04^{\mathrm{de}}$ & $833^{\mathrm{b}}$ \\
\hline $30 \mathrm{~Hz}$ & $0.06 \pm 0^{\mathrm{ab}}$ & $28.74 \pm 0.51^{\mathrm{de}}$ & $0.40 \pm 0.01^{\mathrm{ef}}$ & $213^{\mathrm{c}}$ \\
\hline $60 \mathrm{~Hz}$ & $0.08 \pm 0.02^{\mathrm{b}}$ & $17.59 \pm 3.67^{\mathrm{e}}$ & $0.25 \pm 0.03^{\mathrm{f}}$ & $35^{\mathrm{d}}$ \\
\hline \multicolumn{5}{|c|}{ GSY with MPC } \\
\hline $0 \mathrm{~Hz}$ & $0.03 \pm 0.01^{\mathrm{b}}$ & $165.74 \pm 10.25^{\mathrm{a}}$ & $1.43 \pm 0.01^{\mathrm{a}}$ & $2,436^{\mathrm{a}}$ \\
\hline $15 \mathrm{~Hz}$ & $0.07 \pm 0.04^{\mathrm{ab}}$ & $85.42 \pm 26.94^{\mathrm{b}}$ & $1.14 \pm 0.13^{\mathrm{b}}$ & $400^{c}$ \\
\hline $30 \mathrm{~Hz}$ & $0.07 \pm 0.01^{\mathrm{ab}}$ & $63.7 \pm 4.87^{\mathrm{bcd}}$ & $0.89 \pm 0.09^{\mathrm{c}}$ & $250^{\mathrm{c}}$ \\
\hline $60 \mathrm{~Hz}$ & $0.02 \pm 0.02^{\mathrm{b}}$ & $53.04 \pm 1.64^{\text {bcde }}$ & $0.66 \pm 0.02^{\mathrm{de}}$ & $13^{\mathrm{d}}$ \\
\hline GY & $0.16 \pm 0.01^{\mathrm{a}}$ & $37.52 \pm 2.55^{\text {cde }}$ & $0.79 \pm 0.08^{\mathrm{cd}}$ & $293^{\mathrm{c}}$ \\
\hline
\end{tabular}

$\overline{\mathrm{a}-\mathrm{f}}$ Means within the same column not sharing a common superscript are significantly different $(P<0.05)$.

${ }^{1}$ Also given is the flow characterization (means $\pm \mathrm{SE}$ ) of a commercial strained Greek yogurt (GY). 


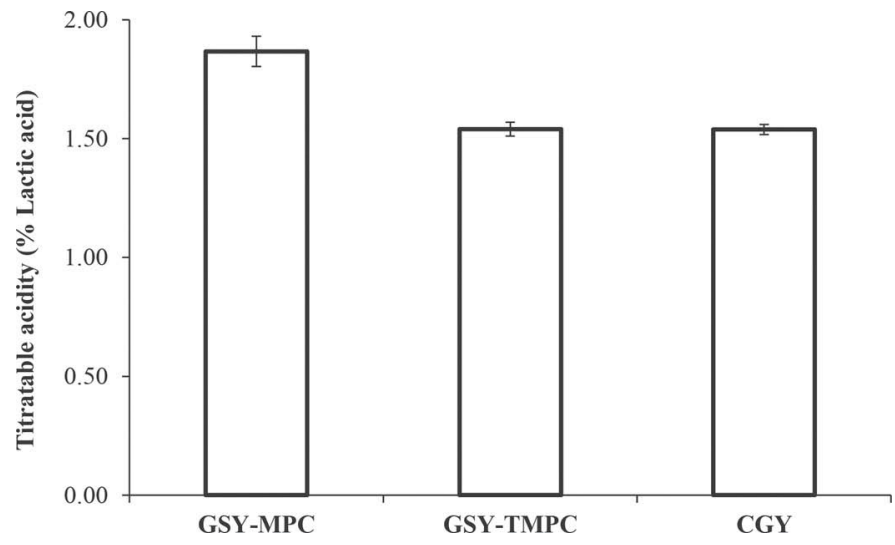

Figure 2. Titratable acidities of Greek-style yogurt (GSY; $9 \% \mathrm{wt} /$ wt, protein) containing either milk protein concentrate (MPC) or $\mathrm{CO}_{2-}$ treated milk protein concentrate (TMPC) and a commercial strained Greek yogurt (CGY) at a pH of $4.5 \pm 0.1$. Error bars indicate SE.

pared with GSY containing MPC. The GSY containing TMPC had lower apparent viscosity $\left(\eta_{\text {app }}\right)$ values than GSY containing MPC across the entire range of shear rate applied ( 1 to $\left.100 \mathrm{~s}^{-1}\right)$. However, the $\eta_{\text {app }}$ at a value at $100 \mathrm{~s}^{-1}$ of commercial GY was higher than that of GSY containing MPC or TMPC. The $n$ value of the commercial GY was 0.16 and was higher than $n$ values of GSY containing MPC or TMPC, indicating a greater shear thinning of GSY subjected to cavitation. A similar $n$ value of a strained commercial GY was reported by Bong and Moraru (2014).

\section{Small Oscillatory Rheology Measurements}

Frequency dependence of $\mathrm{G}^{\prime}$ in GSY containing TMPC and MPC are shown in Figures 3 and 4, respectively. Yogurt gels are known to be frequency dependent with $\mathrm{G}^{\prime}$ increasing with frequency (Ozer et al., 1997). The elastic component $\left(\mathrm{G}^{\prime}\right)$ in yogurts is influenced by the strength and number of nonrelaxing bonds, whereas the viscous component $\left(\mathrm{G}^{\prime \prime}\right)$ is influenced by relaxing bonds (Roefs et al., 1985). The correlation of cavitation intensity (with an increase in rotor speed) and $\mathrm{G}^{\prime}$ in GSY was clearly evident (across the entire frequency range). At high rotor speeds $(60 \mathrm{~Hz})$, a breakdown in gel structure occurred, resulting in a decrease in the elastic moduli of GSY in the frequency range studied. The structural breakdown was greater in GSY containing TMPC. Frequency dependence of $G^{\prime}$ expressed as the slope, $\mathrm{m}$ of the elastic modulus, and frequency curve was $\sim 0.16$ in commercial GY and GSY before cavitation. Following cavitation of GSY containing MPC, the slope dropped to 0.06 at higher rotor speeds (30 and $60 \mathrm{~Hz}$ ), indicating a structural breakdown. Moreover, in GSY containing TMPC, no frequency dependency of $\mathrm{G}^{\prime}$ (determined by the slope of the $\mathrm{G}^{\prime}$ and frequency curve) was evident even at low rotor speeds $(15 \mathrm{~Hz})$. An abrupt decrease occurred in the $G^{\prime}$ values at higher frequency of GSY containing TMPC cavitated at maximum rotor speed, which suggests the occurrence of slippage during the conduct of the experiment.

\section{Penetration Tests}

Hardness/firmness and adhesiveness values of the GSY containing TMPC and MPC are shown in Figures 5 and 6 , respectively. The GSY not subjected to HC had higher hardness, firmness, and adhesiveness values when compared with commercial GY. However, with an increase in rotor speeds, a breakdown occurred in the structure of GSY. The structural breakdown of the GSY containing TMPC was greater when compared with GSY containing MPC. At maximum rotor speeds $(60 \mathrm{~Hz})$, GSY containing TMPC had lower hardness, firmness, and adhesiveness values compared with commercial GY (Figure 5). The GSY containing MPC had identical hardness, firmness, and adhesiveness values as strained commercial yogurts (Figure 6) at maximum rotor speeds $(60 \mathrm{~Hz})$.

\section{Grains}

The occurrence of grains in yogurts could possibly be linked to the denaturation of whey protein and its gelation during the manufacture of acid gels (Remeuf et al., 2003). Grains in the present study were defined as particles with a perimeter of $>1 \mathrm{~mm}$. Commercial GY had 293 grains per gram, whereas GSY containing MPC and TMPC not subjected to cavitation had 2,389 and 2,436 grains per g, respectively, which were significantly higher $(P<0.05)$ than grains in commercial GY. The HC resulted in a steady decrease of the number of grains and was inversely related to rotor speeds employed in the experiment. The GSY containing MPC and TMPC cavitated at maximum rotor speeds $(60$ $\mathrm{Hz}$ ) had 35 and 13 grains per g of yogurt, respectively. Figures 7 and 8 are representative images of grains of GSY with TMPC and MPC, respectively. Figure 9 is a representative image of grains in CGY. Images were captured under a stereomicroscope and processed using Image J software.

\section{Water-Holding Capacities}

The WHC of GSY containing TMPC was significantly higher $(P<0.05)$ to WHC of GSY containing MPC at the rotor speeds studied in this experiment (Figures 10 and 11). As a trend, cavitated GSY had a significantly higher $(P<0.05)$ WHC than commer- 


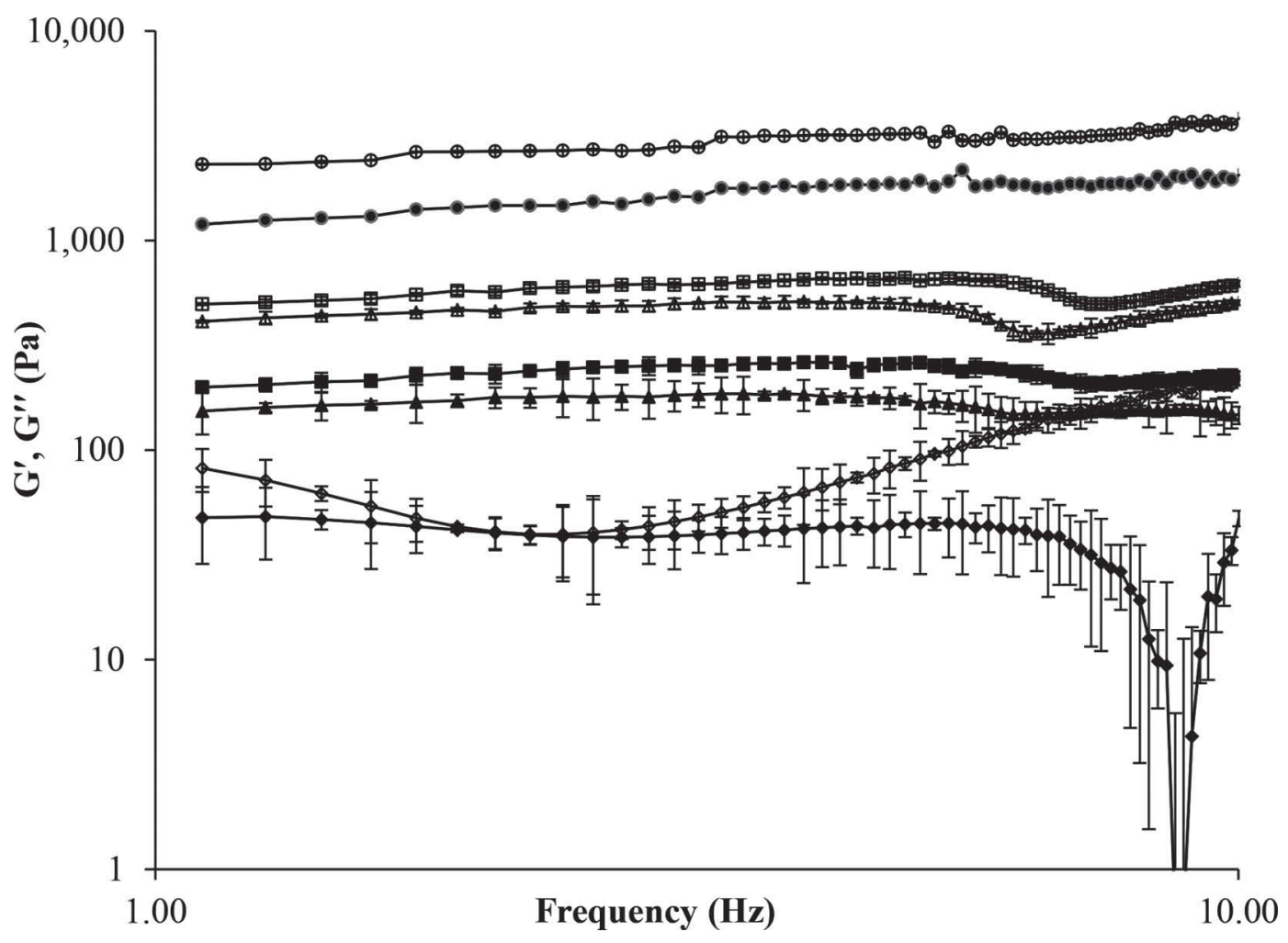

Figure 3. Frequency sweep for Greek-style yogurt $\left(9 \% \mathrm{wt} / \mathrm{wt}\right.$, protein) containing $\mathrm{CO}_{2}$-treated milk protein concentrate at $10^{\circ} \mathrm{C}$ and in the linear viscoelastic region determined by stress sweep experiments. Open symbols are elastic modulus $\left(\mathrm{G}^{\prime}\right)$ values at $0 \mathrm{~Hz}(\mathrm{O}), 15 \mathrm{~Hz}(\square), 30 \mathrm{~Hz}$ $(\Delta)$, and $60 \mathrm{~Hz}(\diamond)$ of rotor speeds. Closed symbols are loss modulus $\left(\mathrm{G}^{\prime \prime}\right)$ values at $(0 \mathrm{~Hz}), \boldsymbol{\square}(15 \mathrm{~Hz}), \boldsymbol{\Delta}(30 \mathrm{~Hz})$, and $\bullet(60 \mathrm{~Hz})$ of rotor speeds. Error bars indicate SE.

cial GY. The increase in WHC of yogurts subjected to cavitation suggests the incorporation of moisture as finely dispersed molecules into the protein matrix and is not expelled by centrifugal forces employed in this experiment. Other potential causes for a lower WHC of commercial GY as compared with a cavitated yogurt could include differences in starter culture strains and heat treatment history of milk used in its manufacture.

\section{DISCUSSION}

Greek-style yogurts containing high-protein dairy ingredients manufactured by the application of membrane filtration processes to milk tend to differ in rheological properties as compared with GY manufactured from skim milk and subjected to the process of dewheying. Meletharayil et al. (2015) reported that high protein acid gels manufactured from reconstituted MPC powders of varying protein content showed variances in gelation times, gelation $\mathrm{pH}$, and final $\mathrm{G}^{\prime}$ values. This was mainly attributed to differences in protein interactions on heating between whey proteins and caseins owing to the altered ionic environment and $\mathrm{Ca}^{2+}$ ion activities of MPC dispersions. The MPC and TMPC powders used for fortification of milk in the manufacture of GSY had significant differences in mineral profiles owing to differences in the method of manufacture. The process of $\mathrm{CO}_{2}$ injection during the manufacturing of TMPC lowers the $\mathrm{pH}$ of milk before and during the process of ultrafiltration/diafiltration to 5.9. At this $\mathrm{pH}$, a partial solubilization of phosphates and calcium (Dalgleish and Law, 1989) partitions it to the permeate stream. The TMPC powder had a $28 \%$ reduction in mineral content and a $33 \%$ reduction in calcium content when compared with control MPC powder. The reduction in acidification times, as observed for GSY containing TMPC, can be correlated with lower mineral content of TMPC powders. Lower phosphates, citrate, and calcium in TMPC powders when compared with control MPC powders reduce the buffering of the GSY base. During the acidification of milk, a maximum in buffering capacity is observed around $\mathrm{pH} 5.1$ and is reported to be the $\mathrm{pH}$ of maximum MCP solubilization (Lucey et al., 1993). Figure 1 shows a steady fall in $\mathrm{pH}$ from 5.1 to 4.6 over time for GSY containing TMPC, whereas a plateau was observed during the acidification of GSY containing MPC. This can be associated with decreased calcium levels in TMPC and removal of MCP during 


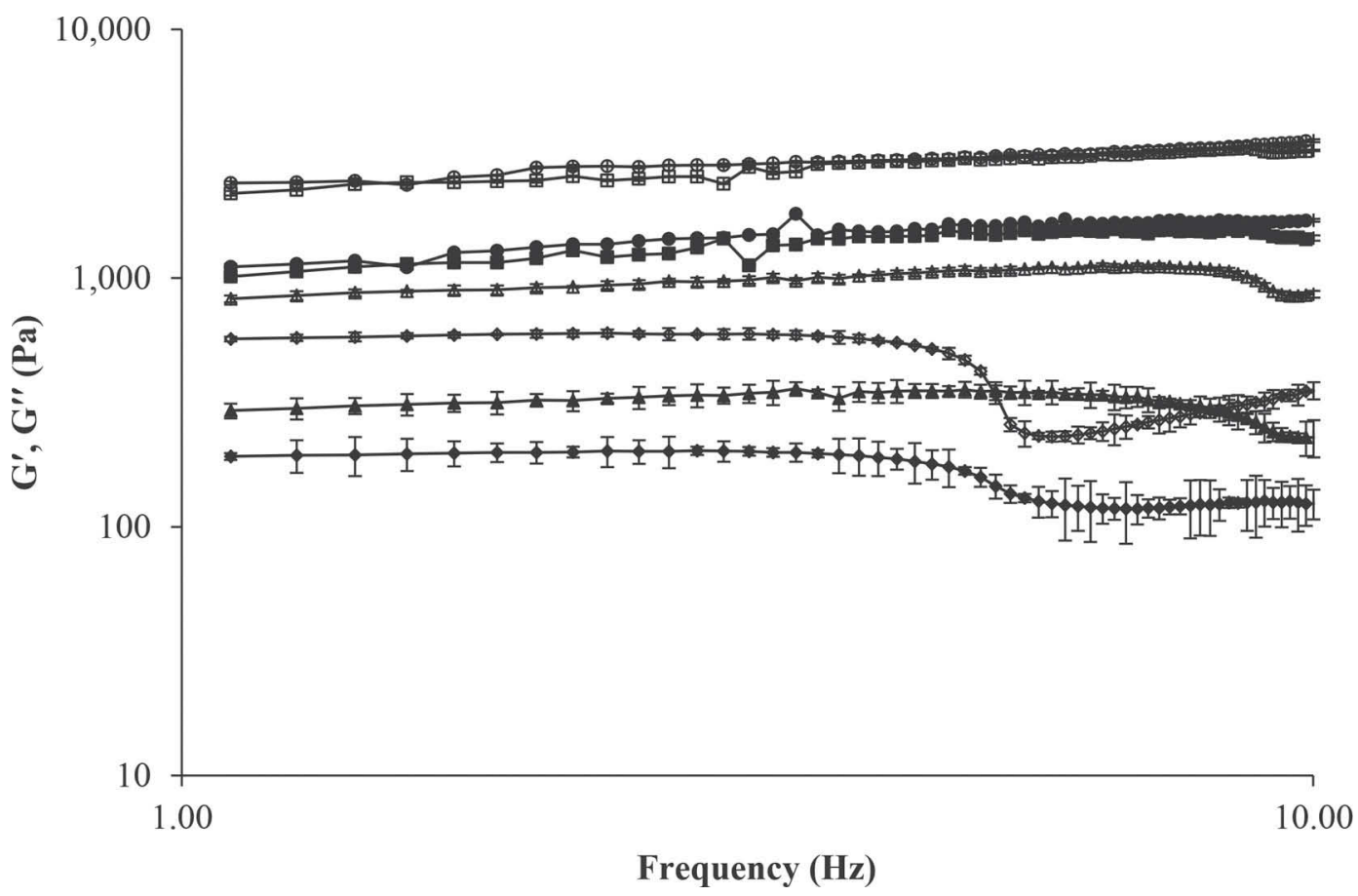

Figure 4. Frequency sweep for Greek-style yogurt (9\% wt/wt, protein) containing milk protein concentrate at $10^{\circ} \mathrm{C}$ and in the linear viscoelastic region determined by stress sweep experiments. Open symbols are elastic modulus $\left(\mathrm{G}^{\prime}\right)$ values at $0 \mathrm{~Hz}(\mathrm{O}), 15 \mathrm{~Hz}(\square), 30 \mathrm{~Hz}(\Delta)$, and 60 $\mathrm{Hz}(\diamond)$ of rotor speeds. Closed symbols are loss modulus $\left(\mathrm{G}^{\prime \prime}\right)$ values at $\bullet(0 \mathrm{~Hz}), \boldsymbol{\square}(15 \mathrm{~Hz}), \boldsymbol{\Delta}(30 \mathrm{~Hz})$, and $\bullet(60 \mathrm{~Hz})$ of rotor speeds. Error bars indicate SE.
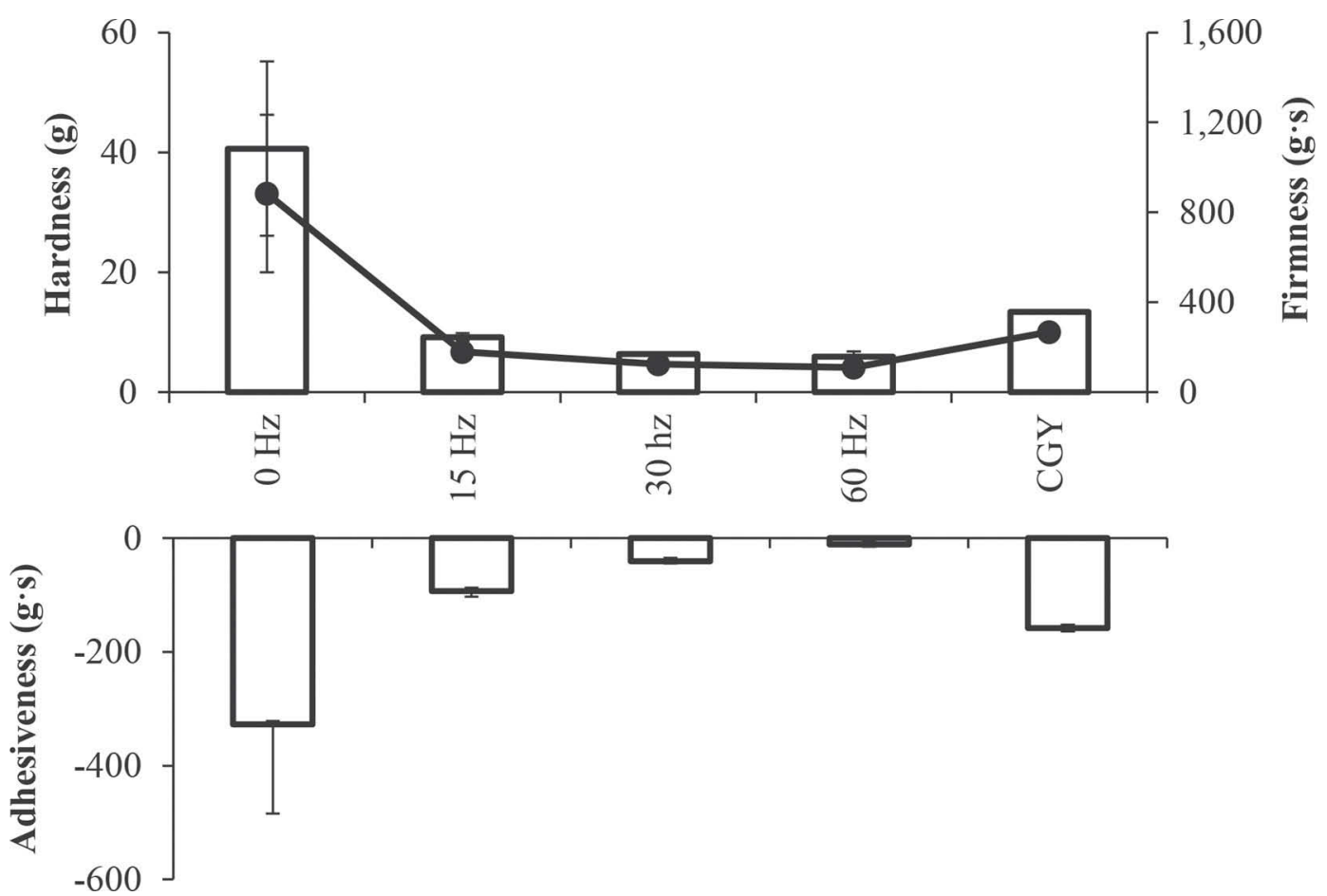

Figure 5. Hardness ( $\square$ ), firmness (- - ) , and adhesiveness values of Greek-style yogurt (9\% wt/wt, protein) containing $\mathrm{CO}_{2}$-treated milk protein concentrate (TMPC) subjected to hydrodynamic cavitation at rotor speeds of $0,15,30$, and 60 Hz. Also shown in the figure are the hardness, firmness, and adhesiveness values obtained on a commercial strained Greek yogurt. Error bars indicate SE. 
the process of TMPC manufacture. The lower buffering observed in GSY containing TMPC was reflected in lower TA values. The TA expressed as percentage lactic acid using the phenolphthalein end point measures the buffering capacity of yogurts to $\mathrm{pH} \sim 8.33$ (Walstra et al., 2005). The lower amount of lactic acid produced to reach a $\mathrm{pH}$ of 4.6 coupled with lower amounts of phosphates and citrates in GSY containing TMPC yielded a product with a lower acidity when compared with GSY containing MPC. Commercial GY had acidity values similar to GSY containing TMPC on account of the removal of lactic acid and minerals during the process of dewheying.

The collapse of cavities during the process of HC leads to the generation of shear forces. Cavitation intensity, which relates to the number of cavitational events occurring during the process of $\mathrm{HC}$, can have a profound influence on the physical and chemical changes in a medium. Previous work by Badve et al. (2015) reported that in $\mathrm{HC}$ brought about by a stator-rotor assembly design (a similar design was used in our study), the cavitation intensity was directly proportional to rotor speeds. Increase in cavitational intensities resulted in physicochemical changes of GSY. The increase in WHC of GSY with an increase in rotor speeds related to the reported increase in the hydration of biopolymers in food subjected to HC (Mawson and Knoerzer, 2007).
Literature also cites altered protein conformation and structure when subjected to high-intensity ultrasonication leading to increased protein solubility and hydration (Moulton and Wang, 1982; Morel et al., 2000). The breakdown of gel structure was evident in steady shear rate sweeps of GSY. The consistency coefficient values $\kappa$ and $\eta_{\text {app }}$ values of GSY were lowest at maximum rotor speeds GSY had greater shear thinning behavior as compared with commercial GY across the shear rates applied in the study indicating a lower tolerance to shear. A similar trend was reported by Bong and Moraru (2014) in GSY manufactured from milk fortified with micellar casein concentrates. A possible explanation could be the high gelation $\mathrm{pH}$ of dispersions containing MPC as protein sources. Meletharayil et al. (2015) reported an increase in gelation $\mathrm{pH}$ and decrease in gelation times when high protein acid gels were manufactured from reconstituted MPC powders. Gelation at a higher $\mathrm{pH}(>5.5)$ could exclude whey proteins from the acid gel network (isoelectric point, pI, 5.3) leading to a gel network of hydrophobically associated caseins that would shear on the application of low amounts of stress. A similar phenomenon may also be occurring in acid gels made from unheated milk that are reported to have a lower shear tolerance and elastic modulus owing to the exclusion of whey proteins in the formation of the acid gel structure (Anema et al.,
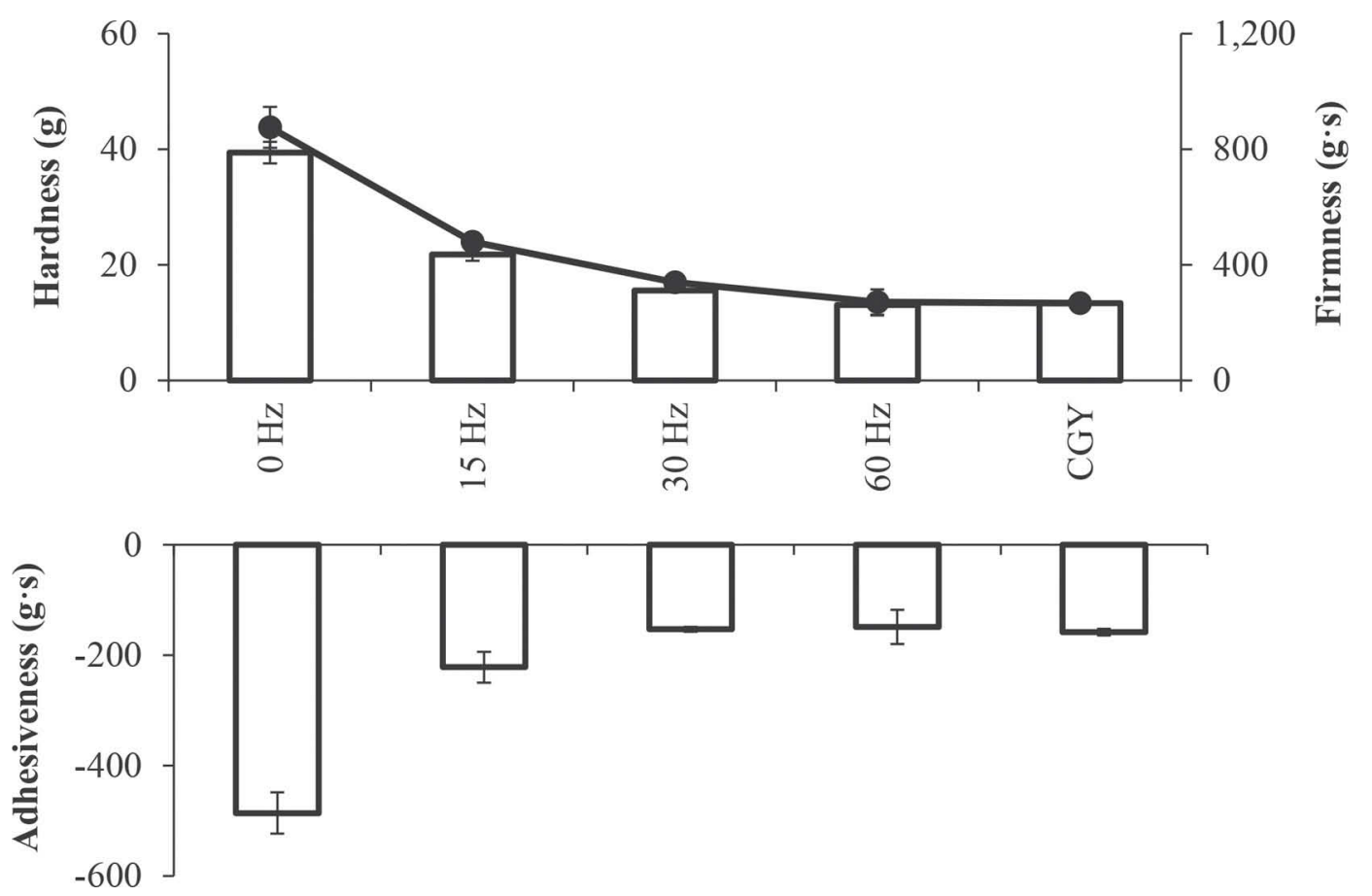

Figure 6. Hardness ( $\square$ ), firmness (- - ), and adhesiveness values of Greek-style yogurt (9\% wt/wt, protein) containing milk protein concentrate (MPC) subjected to hydrodynamic cavitation at rotor speeds of $0,15,30$, and $60 \mathrm{~Hz}$. Also shown in the figure are the hardness, firmness, and adhesiveness values obtained on a commercial strained Greek yogurt. Error bars indicate SE. 


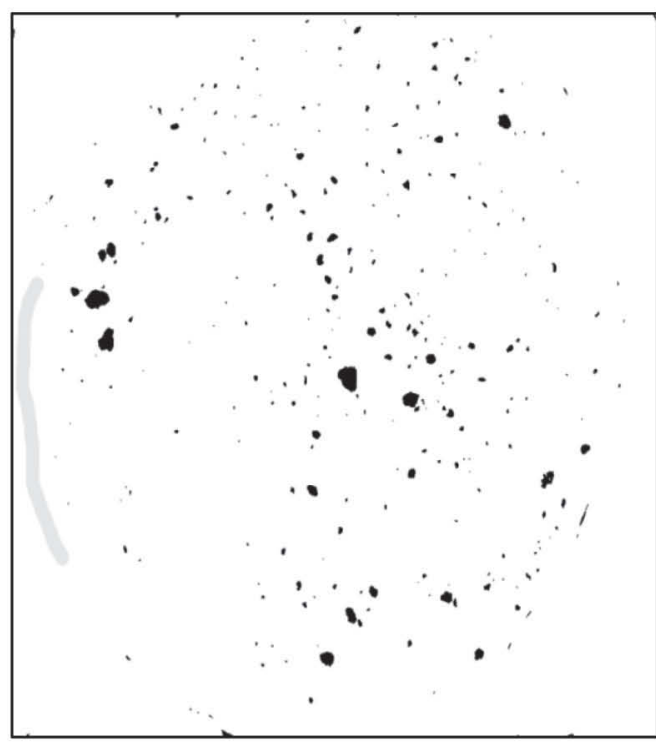

$0 \mathrm{~Hz}$

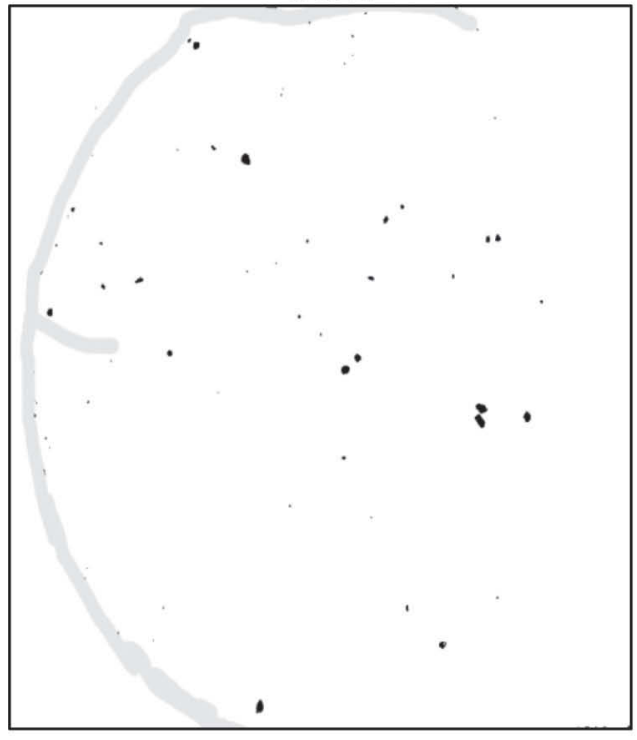

$30 \mathrm{~Hz}$

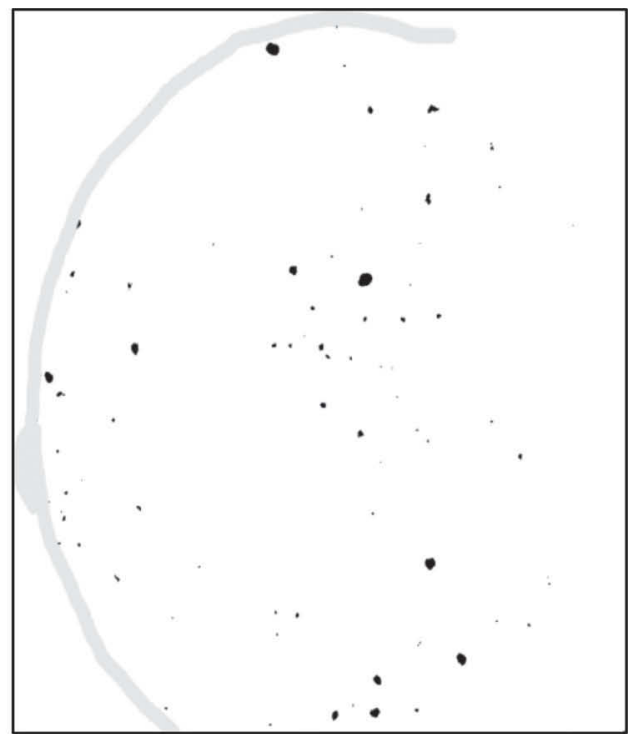

$15 \mathrm{~Hz}$

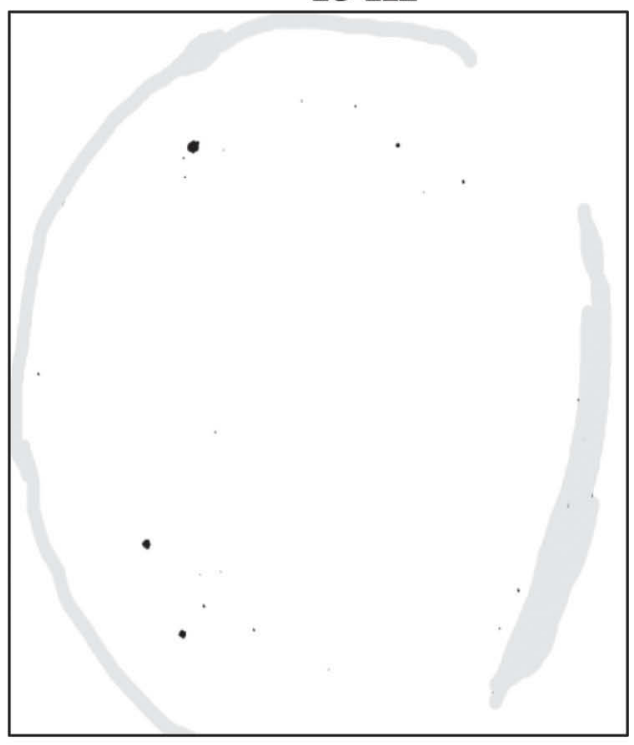

$60 \mathrm{~Hz}$

Figure 7. Representative stereomicroscopic images of grains in Greek-style yogurts ( $9 \%$ wt/wt, protein) containing CO ${ }_{2}$-treated milk protein concentrate and subjected to cavitation at rotor speeds of $0,15,30$, and $60 \mathrm{~Hz}$. Grains appear as dark objects and are further analyzed using ImageJ software (US National Institutes of Health, Bethesda, MD).

2005). On the contrary, GY from skim milk (employing the dewheying step) have a gelation $\mathrm{pH}$ of $\sim 5.1$ and would include in the gel network caseins cross-linked by whey proteins leading to a gel with greater amounts shear tolerance (Lucey et al., 1997).

The GSY containing TMPC had lower $\kappa$ values as compared with the GSY containing MPC. A decrease in MCP in GSY containing TMPC could influence the extent of casein crosslinking during acid gelation leading to a lower number and strength of bonds that could influence $\kappa$ values. A similar correlation was observed for the frequency dependence of $\mathrm{G}^{\prime}$ values with GSY yogurts containing TMPC having a lower $\mathrm{G}^{\prime}$ when cavitated at higher rotor speeds than GSY containing MPC (Figures 3 and 4). Commercial GY showed a frequency dependence of $\mathrm{G}^{\prime}$ similar to those of noncavitated GSY (slope of $\mathrm{G}^{\prime}$ and frequency curve of $\sim 0.16$ for commercial GY and noncavitated GSY). With increasing rotor speeds, an increase in the cavitational intensity may lead to the breakdown of nonrelaxing bonds that contribute to $\mathrm{G}^{\prime}$ in GSY. Weaker intermicellar casein crosslinking in GSY containing TMPC owing to a lower 
MCP content may have resulted in a greater decline in $\mathrm{G}^{\prime}$ when subjected to the forces of cavitation. A similar correlation was seen in the penetration tests where GSY containing TMPC had a lower hardness, firmness, and cohesiveness values than GSY with MPC across the rotor speeds applied in the experiment (Figures 5 and 6). On HC, acid gels have decreased ability to resist compressive and shear forces due to the breakdown of the bonds. A decrease in adhesiveness values of GSY with increasing cavitational intensity can be correlated with improved mouthfeel during its consumption and is generally not associated with GSY fortified with milk protein powders (Desai et al., 2013).

Subjecting GSY to HC decreased the number of grains thought to be formed as a result of local stresses developed during the gelation process (Lucey et al., 1997). These grains could serve as nuclei for the cavitation bubble to form, grow, and explode, thus releasing shear forces resulting in their breakdown (Figures 7 and 8). Overall, in the current set of experiments employed for the manufacture of GSY, the use of TMPC as a protein source in conjunction with $\mathrm{HC}$ could help achieve

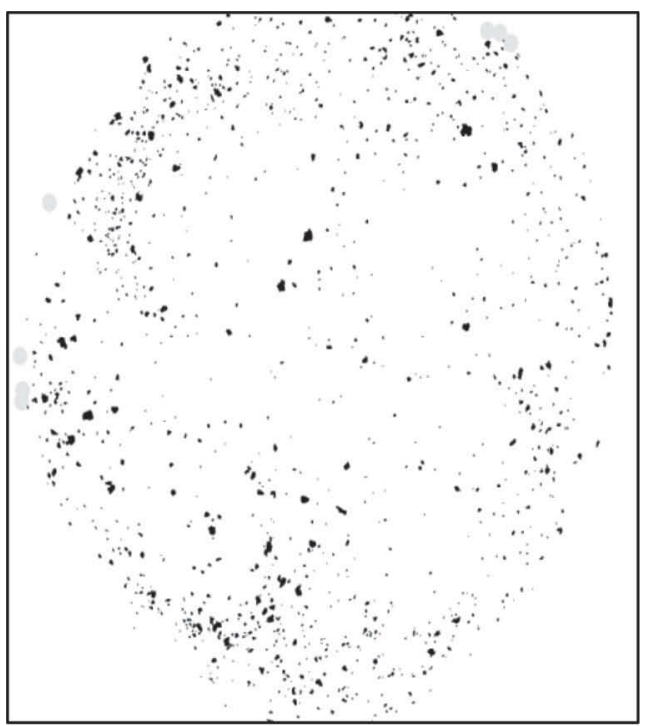

$\mathbf{0 ~ H z}$

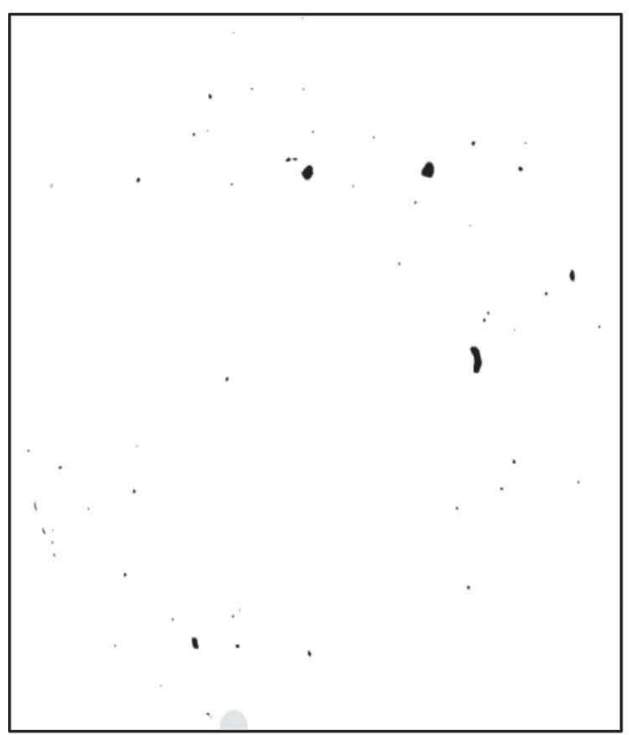

$30 \mathrm{~Hz}$

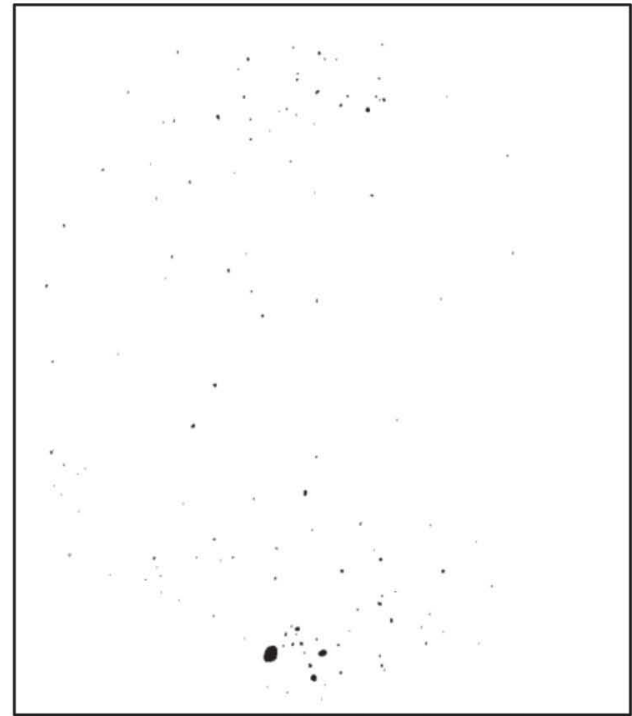

$15 \mathrm{~Hz}$

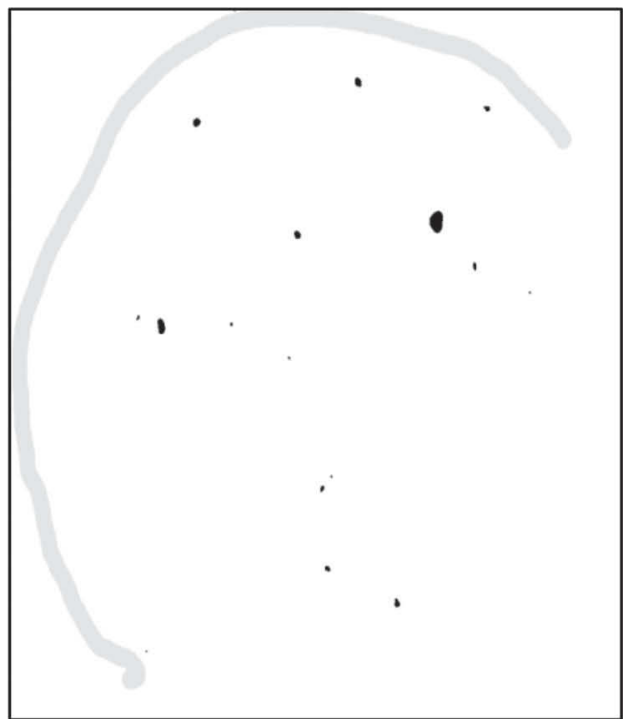

$60 \mathrm{~Hz}$

Figure 8. Representative stereomicroscopic images of grains in Greek-style yogurts (9\% wt/wt, protein) containing milk protein concentrate and subjected to cavitation at rotor speeds of $0,15,30$, and $60 \mathrm{~Hz}$. Grains appear as dark objects and are further analyzed using ImageJ software (US National Institutes of Health, Bethesda, MD). 


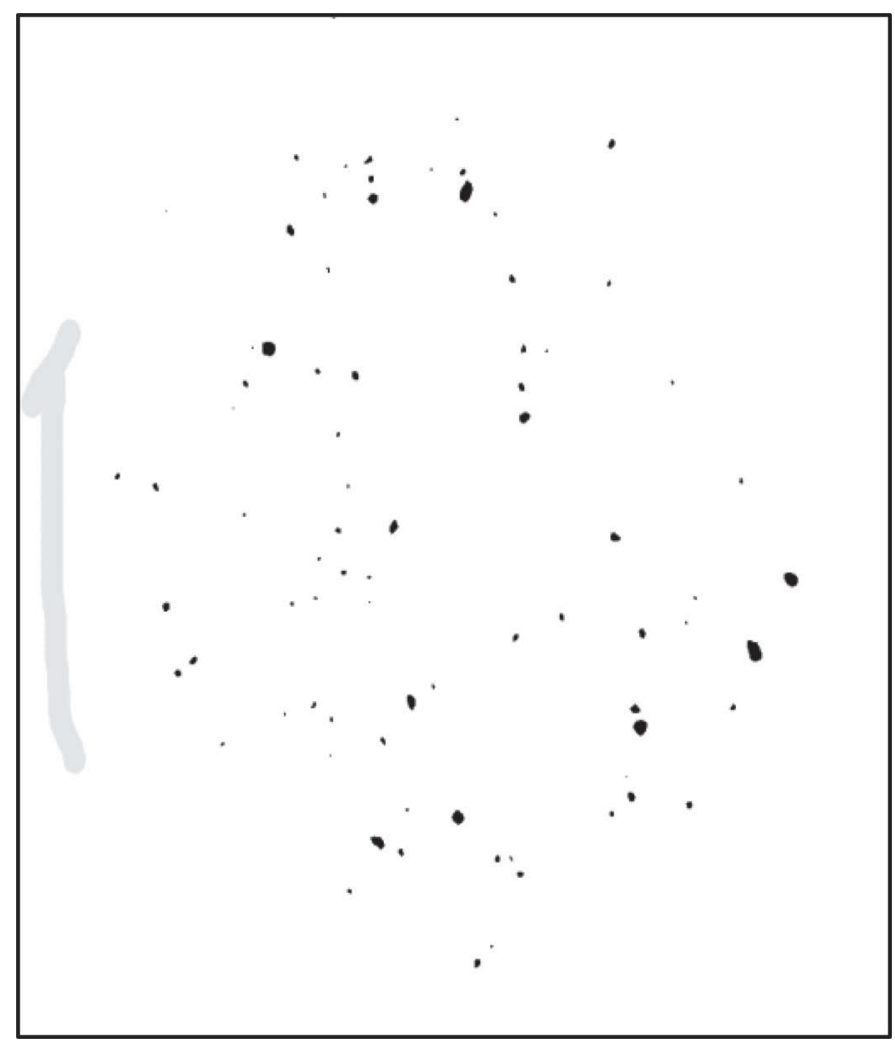

Figure 9. Representative stereomicroscopic image of grains in commercial Greek yogurt (9\% wt/wt, protein). Grains appear as dark objects and are further analyzed using ImageJ software (US National Institutes of Health, Bethesda, MD).

comparable TA values, rheological properties, and microstructure to that of a commercial strained GY.

\section{CONCLUSIONS}

The use of $\mathrm{CO}_{2}$-treated MPC in conjunction with hydrodynamic cavitation can be used to control the increased viscosity, firmness, and acidity that is encountered in the manufacture of GSY containing added milk protein ingredients. An increase in cavitational intensities brought about by an increase in rotor speed led to a decrease in the frequency dependence of $\mathrm{G}^{\prime}$, indicating a breakdown of protein interactions. A decrease in the buffering capacities of the GSY base achieved by the removal of minerals using a combination of $\mathrm{CO}_{2}$ treatment in tandem with UF and diafiltration led to comparable acidity values of GSY and GY at $\mathrm{pH}$ 4.6. Identical hardness, firmness, and adhesiveness values were observed between a commercial GY and GSY containing TMPC subjected to cavitation. Similar microstructure was also observed between commercial GY and GSY subjected to cavitation. The ability to scale up the process of hydrodynamic cavitation industrially

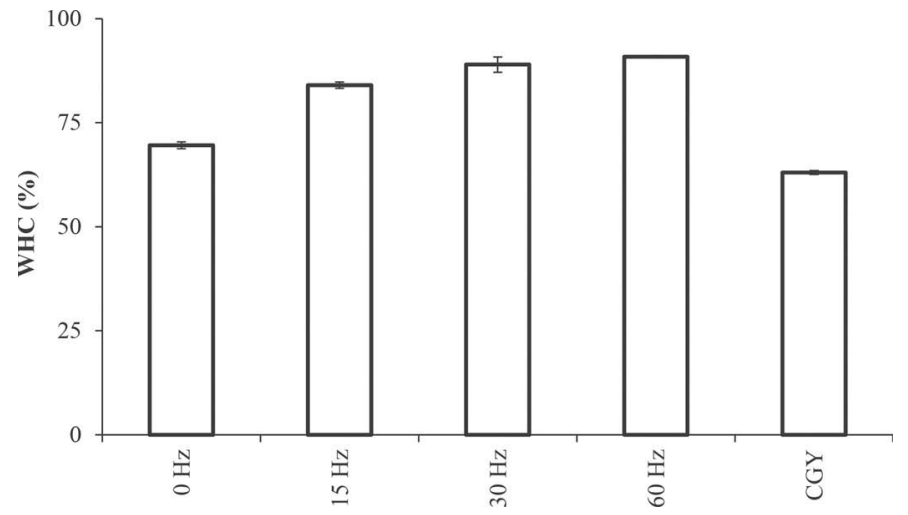

Figure 10. Water-holding capacities (WHC) of Greek-style yogurt (9\% wt/wt, protein) containing $\mathrm{CO}_{2}$ treated milk protein concentrate subjected to hydrodynamic cavitation at rotor speeds of $0,15,30$, and $60 \mathrm{~Hz}$. Also shown in the figure is the WHC of a commercial strained Greek yogurt. Error bars indicate SE.

and the ease of controlling the event of cavitation that can influence final textural properties of the product make this technology promising for large-scale industrial applications. The process used in this study could be a solution to the vexing problem of acid whey disposal faced by the dairy companies manufacturing GY.

\section{ACKNOWLEDGMENTS}

The authors acknowledge the financial support of the Midwest Dairy Foods Research Center (Brookings, SD), the Agricultural Utilization Research Institute (St. Paul, $\mathrm{MN}$ ), and the Agricultural Experiment Station (South Dakota State University; HATCH3ADP12-328100).

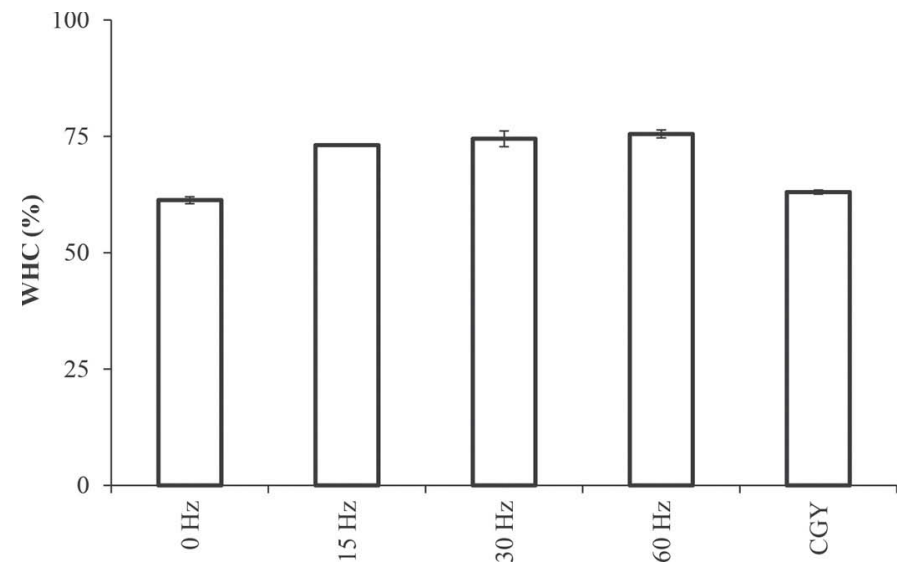

Figure 11. Water-holding capacities (WHC) of Greek-style yogurt (9\% wt/wt, protein) containing milk protein concentrate subjected to hydrodynamic cavitation at rotor speeds of $0,15,30$, and $60 \mathrm{~Hz}$. Also shown in the figure is the WHC of a commercial strained Greek yogurt. Error bars indicate SE. 


\section{REFERENCES}

Anema, S. G., S. Lauber, S. K. Lee, T. Henle, and H. Klostermeyer. 2005. Rheological properties of acid gels prepared from pressureand transglutaminase-treated skim milk. Food Hydrocoll. 19:879887.

Badve, M. P., T. Alpar, A. B. Pandit, P. R. Gogate, and L. Csoka. 2015. Modeling the shear rate and pressure drop in a hydrodynamic cavitation reactor with experimental validation based on KI decomposition studies. Ultrason. Sonochem. 22:272-277.

Bong, D. D., and C. I. Moraru. 2014. Use of micellar casein concentrate for Greek-style yogurt manufacturing. Effect on processing and product properties. J. Dairy Sci. 97:1259-1269.

Dalgleish, D. G., and A. J. R. Law. 1989. pH-induced dissociation of bovine casein micelles. II. Mineral solubilization and its relation to casein release. J. Dairy Res. 56:727-735.

Desai, N. T., L. Shepard, and M. A. Drake. 2013. Sensory properties and drivers of liking for Greek yogurts. J. Dairy Sci. 96:7454-7466.

Earnshaw, R. G. 1998. Ultrasound: A new opportunity for food preservation. Pages 183-192 in Ultrasound in Food Processing. M. J. W. Povey and T. J. Mason, ed. Blackie Academic \& Professional, London, UK.

Gogate, P. R., and G. S. Bhosale. 2013. Comparison of effectiveness of acoustic and hydrodynamic cavitation in combined treatment schemes for degradation of dye wastewaters. Chemical Engineering and Processing: Process Intensification 71:59-69.

Lucey, J. A., B. Hauth, C. Gorry, and P. F. Fox. 1993. The acid-base buffering properties of milk. Milchwissenschaft 48:268-272.

Lucey, J. A., C. T. Teo, P. A. Munro, and H. Singh. 1997. Rheological properties at small (dynamic) and large (yield) deformations of acid gels made from heated milk. J. Dairy Res. 64:591-600.

Marella, C., P. Salunke, A. C. Biswas, A. Kommineni, and L. E. Metzger. 2015. Manufacture of modified milk protein concentrate utilizing injection of carbon dioxide. J. Dairy Sci. 98:3577-3589.
Mawson, R., and K. Knoerzer. 2007. A brief history of the application of ultrasonics in food processing. 19th ICA Congress, Madrid, 2007. Accessed Aug. 18, 2015. http://www.sea-acustica.es/ WEB_ICA_07/fchrs/papers/ult-09-004.pdf.

Meletharayil, G. H., H. A. Patel, and T. Huppertz. 2015. Rheological properties and microstructure of high protein acid gels prepared from reconstituted milk protein concentrate powders of different protein content. Int. Dairy J. 47:64-71.

Morel, M. H., P. Dehlon, J. C. Autran, J. P. Leygue, and C. BarL'Helgouac'h. 2000. Effects of temperature, sonication time, and power settings on size distribution and extractability of total wheat flour proteins as determined by size-exclusion high-performance liquid chromatography. Cereal Chem. 77:685-691.

Moulton, K. J., and L. C. Wang. 1982. A pilot-plant study of continuous ultrasonic extraction of soybean protein. J. Food Sci. 47:11271129 .

Ozer, B. H., R. K. Robinson, A. S. Grandison, and A. E. Bell. 1997. Comparison of techniques for measuring the rheological properties of Labneh (concentrated yogurt). Int. Dairy J. 50:129-133.

Remeuf, F. S. Mohammed, I. Sodini, and J. P. Tissier. 2003. Preliminary observations on the effects of milk fortification and heating on microstructure and physical properties of stirred yogurt. Int Dairy J. 13:773-782.

Roefs, S. P. F. M., P. Walstra, D. G. Dagleish, and D. S. Horne. 1985. Preliminary note on the change in casein micelles caused by acidification (skim milk). Neth. Milk Dairy J. 39:119-122.

USDA. 2014. Dairy products: Per capita consumption, United States (Annual). Accessed Aug. 18, 2015. http://www.ers.usda.gov/dataproducts/dairy-data.aspx.

Walstra, P., J. T. Wouters, and T. J. Geurts. 2005. Dairy Science and Technology. CRC Press, Boca Raton, FL. 